\title{
Abortion as a Process of Birth Limiting Rather than Spacing among Educated Urban Couples in West Bengal, India
}

\section{Sumoni Mukherjee}

Despite the high level of usage of traditional contraceptive methods, particularly among the urban and educated couples, the eastern Indian state of West Bengal has achieved the replacement level of fertility. This paper attempts to understand the patterns, dynamics of contraceptive use and associated outcomes (method failure and abortions) during the interpregnancy intervals among the urban educated-couples who ever used any traditional contraceptive methods in Howrah, West Bengal using both quantitative and qualitative approach. The findings showed that the use of traditional contraceptive methods was high due to lower comprehensive knowledge and misconceptions about modern methods, particularly among men. High prevalence of unintended pregnancies and induced abortions was observed, particularly for traditional contraceptive users. The calculated unintended pregnancy rate and ratio in the study population were 235 per 1,000 pregnancies and 570 per 1,000 women, respectively. Similarly, the calculated rate of induced abortion was 78 per 1,000 pregnancies with an abortion ratio of 99 per 1,000 live births. Due to the motivation to have small families, couples if they had at least one surviving child, opted to regulate their unintended pregnancies with induced abortion, especially among only traditional contraceptive users. This indicates that women considered abortion as a process of birth limiting rather than spacing to maintain the desired family size and the choice of contraceptives determining number of pregnancies.

Keywords: traditional contraceptive methods, unintended pregnancy, induced abortion

${ }^{1}$ Gokhale Institute of Politics \& Economics, Pune, India. Email: sumoni.mukherjee@gmail.com 


\section{Introduction}

In developing countries, almost 40 percent of pregnancies are unintended and 58 percent of them end up with induced abortion (World Health Organization, 2012). Though many women in these countries like to delay next pregnancy or want to stop child bearing, still rely on not to use any contraceptive or depend on less effective methods (Peterson, Darmstadt \& Bongaarts, 2013). In the last few decades attitude towards contraception in India has changed with the promotion of the modern contraceptive methods by the government. Despite this around one-fourth of the births in India between 1989 and 2005 were unwanted (International Institute for Population Sciences \& ORC Macro, 1995; 2000; 2007). Moreover, many of the states (viz., Goa, Assam and Kerala) including West Bengal preferred traditional methods of contraception over modern methods (Husain \& Dutta, 2016; Ram, Shekhar \& Chowdhury 2014). Number of studies in India show strong association between desires to small family, unintended contraceptive use, unplanned pregnancy and induced abortion (Mishra, Retherford, Nair, \& Feeney, 1999; Chacko, 2001; Ganatra \& Hirve, 2002; Ravindran \& Balasubramanian, 2004; Visaria, Ramachandran, Ganatra, \& Kalyanwala, 2004) and between women's education and induced abortion (Chacko, 2001; Ganatra \& Hirve, 2002; Marston \& Cleland, 2003; Ravindran \& Balasubramanian, 2004; Pallikadavath \& Stones, 2006; Biswas, Bhunia, \& Mukherjee; 2016). On other hand, several studies have also examined the effect of inter-pregnancy intervals with adverse maternal and infant health outcomes (Viz., low birth weight, premature births, child growth, breastfeeding, infant and child mortality, maternal deaths and others) and well documented in the demographic literature (Whitworth, \& Stephenson, 2002; Rutstein S 2005; CondeAgudelo, Rosas-Bermúdez, \& Kafury-Goeta, 2006; Wendt, Gibbs, Peters et al., 2012 among others). However, studies on the evidence linking contraceptive use during the interval between pregnancies are limited and lacking in developing countries including India (Hogue, Schoenfelder, Gesler \& Shachtman, 1978; Huber, Hogue, Stein, Drews et al., 2006; White, Teal, \& Potter, 2015, Weisband, Keder, Keim, \& Gallo, 2017 among others).

This paper explores the patterns of contraceptive use, contraceptive choices, decision making process, causes and consequences associated with a selected contraceptive method, and the mechanisms to handle unwanted pregnancy during inter-pregnancy intervals among ever users of traditional contraceptive method. Exploration of use of traditional contraception methods, consequences and associated pregnancy outcomes during the inter-pregnancy intervals, are a little researched area globally and this paper attempts in this direction focusing on the topic in India. The paper 
begins with the background profile, levels and trends of fertility and contraceptive use in the state of West Bengal, using the census and large scale surveys conducted at state, district and national levels. This is followed by a presentation on the characteristics and patterns of contraceptive in the study population using both quantitative and qualitative primary data and the study findings discussed in detail.

\section{Profile, Levels and Trends of Fertility and Contraceptive Use in the State of West Bengal}

The state of West Bengal is located in Eastern India on the Bay of Bengal. It is the fourth-most populous state of India and seventh most populous sub-national entity in the world. According to the 2011 Census, it consists of 7.5 percent of India's population with over 91 million inhabitants, and about one-third (32 percent) of the state population living in urban areas. More than three-fourths ( 77.1 percent) of the state population and 71.2 percent of female population are literate (Registrar General, India, 2013). All direct and indirect estimates (Census India, System Registration System [SRS] and National Family Health Surveys [NFHS]) show the total fertility rate in the state was below the national average and faster decline also observed. According to the SRS estimates, the total fertility rate (TFR) in the state declined from 4.2 to 1.6 children per woman compared to 4.5 to 2.4 at the national level during the periods 1981 and 2015. Four rounds of NFHS (1992-93, 199899, 2005-06 and 2015-16) also suggests a clear slowdown in fertility in the state from 2.9 to 1.8 , whereas at all-India level from 3.4 to 2.2 per woman between the periods 1992-93 and 2015-16 respectively (Table 1). Moreover, urban TFR in the state achieved the replacement level in 1989 (Basu, 2005). It should be noted here that fertility transition in West Bengal started well before independence and the capital of the state is amongst the forerunners of fertility decline alongside the southern and coastal areas of India (Basu, 2005). Moreover, the state government has been quite indifferent to population policy and never had the kind of aggressive or even efficient family planning campaign or program that many other parts of India have embraced at various times (Basu \& Amin, 2000). On the other hand, four rounds of the NFHS and DLHS data show a concurrent prevalence of traditional and modern contraceptive use in the state. According to the latest National Family Health Survey (NFHS-4) data, the current contraceptive prevalence in the state is highest among the Indian states. The contraceptive prevalence rate (CPR) for any method increased from 58 to 71 percent between NFHS-1 and 4 compared to 41 and 54 percent at the national level. The traditional contraceptive method use has remained more or less constant (19-21 percent) in the state but at the national level 
it has shown an increasing trend from 4.2 to 7.4 percent between NFHS-1 and 3. However, the NFHS- 4 data shows a decline in the practice of both traditional methods and female sterilization as contraception (IIPS \& Macro 2016).

Table 1: Levels and trends in fertility and contraceptive use by residence, West Bengal and India

\begin{tabular}{|c|c|c|c|c|c|c|}
\hline \multirow[b]{2}{*}{ Indicator and Period } & \multicolumn{3}{|c|}{ West Bengal } & \multicolumn{3}{|c|}{ All-India } \\
\hline & Total & Rural & Urban & Total & Rural & Urban \\
\hline \multicolumn{7}{|l|}{ Total Fertility Rate* } \\
\hline $1981(\mathrm{SRS})^{\dagger}$ & 4.2 & 4.8 & 2.4 & 4.5 & 4.8 & 3.3 \\
\hline $1991(\mathrm{SRS})^{\dagger, \pm \$}$ & 3.2 & 3.6 & 2.1 & 3.6 & 3.9 & 2.7 \\
\hline $2001(\text { SRS) })^{*}$ & 2.4 & 2.7 & 1.6 & 3.1 & 3.4 & 2.3 \\
\hline 2011 (SRS) & 1.7 & 1.9 & 1.3 & 2.4 & 2.7 & 1.9 \\
\hline 2015 (SRS) & 1.6 & 1.7 & 1.2 & 2.3 & 2.5 & 1.8 \\
\hline 1992-93 (NFHS-1) & 2.92 & 3.25 & 2.14 & 3.36 & 3.64 & 2.68 \\
\hline 1998-99 (NFHS-2) & 2.29 & 2.49 & 1.69 & 2.85 & 3.07 & 2.27 \\
\hline 2005-06 (NFHS-3) & 2.27 & 2.54 & 1.59 & 2.68 & 2.98 & 2.06 \\
\hline 2015-16 (NFHS-4) & 1.8 & 1.9 & 1.6 & 2.2 & 2.4 & 1.8 \\
\hline \multicolumn{7}{|l|}{ Contraceptive Use - Any method (\%) } \\
\hline 1992-93 (NFHS-1) & 57.7 & 56.0 & 62.0 & 40.7 & 37.1 & 51.1 \\
\hline 1998-99 (NFHS-2) & 66.6 & 64.5 & 73.4 & 48.2 & 44.7 & 58.2 \\
\hline 2005-06 (NFHS-3) & 71.2 & 69.5 & 75.5 & 56.3 & 53.0 & 64.0 \\
\hline 2015-16 (NFHS-4) & 70.9 & 71.8 & 69.0 & 53.5 & 51.7 & 57.2 \\
\hline \multicolumn{7}{|l|}{ Any Traditional Methods (\%) } \\
\hline 1992-93 (NFHS-1) & 19.6 & 31.0 & 40.0 & 4.2 & 3.5 & 5.6 \\
\hline 1998-99 (NFHS-2) & 18.5 & 15.9 & 26.6 & 5.0 & 4.4 & 6.7 \\
\hline 2005-06 (NFHS-3) & 20.7 & 18.9 & 25.6 & 7.4 & 7.2 & 7.9 \\
\hline 2015-16 (NFHS-4) & 13.9 & 13.1 & 16.0 & 5.7 & 5.7 & 5.9 \\
\hline \multicolumn{7}{|l|}{ Quality of Family Planning Services } \\
\hline $\begin{array}{l}\text { Current users reported side effects of } \\
\text { method (\%) (NFHS-4, 2015-16)** }\end{array}$ & 49.8 & 50.1 & 49.0 & 46.5 & 45.0 & 50.1 \\
\hline
\end{tabular}

Notes: SRS (sample registration system) is based on a dual record system, consists of continuous enumeration of births and deaths in a sample of villages/urban blocks by a resident part time enumerator, and an independent six monthly retrospective survey by a full time supervisor; NFHS (National Family Health Survey) is a large-scale, multi-round survey conducted in a representative sample of households in India and the state of West Bengal; The differences between the NFHS and SRS estimates may be caused partly due to age displacement/ age misreporting in NFHS, whereas in the SRS, births are recorded during the year in which they occur.

*Total fertility rate (children per woman) refers to the respective calendar year (for SRS); and 1-36 months preceding the survey (for NFHS). NFHS-1, 2, 3 \& 4 refers to the periods of (approximately) 1990-91, 199698, 2003-05 and 2013-15, respectively. All-India TFR estimates excludes †Mizoram; $\$$ Nagaland (Rural) $\$$ Jammu \& Kashmir, due to non-receipt of returns; 'Traditional methods include Rhythm and withdrawal methods only; ** Based on current users of female sterilization, IUD/PPIUD, injectables and pill who started using the method in the past 5 years.

Source: NFHS-1: IIPS (1995), PRC and IIPS (1994); NFHS-2: IIPS and ORC Macro (2000 \& 2001); NFHS-3: IIPS and ORC Macro (2007a \& b); NFHS-4: IIPS and ORC Macro (2016 a \& b, National and State Fact Sheets); SRS: India, Registrar General (various years). 
According to the District Level Household and Facility Surveys (DLHS-2, $3 \&$ 4), the average number of children ever born, birth order three and above, induced abortion rates and the use of traditional contraceptive methods among currently married women has declined rapidly between the DLHS-2 and DLHS-3 periods. However, the contraceptive prevalence rate and the unmet need for contraception (spacing or limiting) have remained more or less constant at the both State and Howrah district. Between the DLHS-2 and DLHS-3 period the contraceptive prevalence rate slightly declined (from 74 to 72 percent and 77 to 73 percent at state and Howrah district levels, respectively) and the total unmet need remained at 1112 and 8-11 percent, at state and district levels, respectively. Similar to the state pattern, the unmet need for limiting methods is higher than that for spacing methods at Howrah district (Table 2).

Table 2: Levels and Trends in Fertility and Contraceptive Use, Howrah and West Bengal, India

\begin{tabular}{|c|c|c|c|c|c|c|}
\hline \multirow[b]{2}{*}{ Indicator and Period } & \multicolumn{3}{|c|}{ Howrah (District) } & \multicolumn{3}{|c|}{ West Bengal (State) } \\
\hline & $2002-04$ & $2007-08$ & $2012-13$ & $2002-04$ & $2007-08$ & $2012-13$ \\
\hline \multicolumn{7}{|l|}{ Fertility } \\
\hline Mean no. of children ever born ${ }^{*}$ & 3.6 & 3.3 & 2.9 & 3.7 & 3.6 & 2.9 \\
\hline Birth order of 3 and above $(\%)$ & 25.6 & 23.7 & 16.4 & 31.0 & 27.8 & 19.8 \\
\hline Induced abortion (\%) & 7.0 & 2.4 & 1.3 & 5.8 & 3.2 & 1.9 \\
\hline \multicolumn{7}{|l|}{ Contraceptive Use } \\
\hline Current use (any method) (\%) & 77.6 & 75.4 & 73.1 & 74.1 & 72.0 & 71.8 \\
\hline Any traditional method $^{t}(\%)$ & 22.4 & 20.4 & 15.0 & 23.0 & 18.8 & 13.1 \\
\hline \multicolumn{7}{|l|}{ Unmet Need for Family Planning } \\
\hline $\operatorname{Total}^{\S}(\%)$ & 8.7 & 8.4 & 10.8 & 11.0 & 11.1 & 12.1 \\
\hline Spacing $(\%)$ & 3.5 & 2.7 & 4.8 & 4.4 & 4.2 & 4.9 \\
\hline Limiting $(\%)$ & 5.1 & 5.7 & 6.0 & 6.6 & 7.4 & 7.2 \\
\hline
\end{tabular}

Note: District Level Household and facility Survey (DLHS) is a household survey to provide reproductive and child health related database at district level across 611 districts in India (19 districts of West Bengal state including Howrah district) conducted during the periods 2002-04 (DLHS-2), 2007-08 (DLHS-3) and 2012-13 (DLHS-4). *average number of children among the currently married women aged 40-44 years (DLHS-2) and 40-49 years (DLHS-384). 'tamong the currently married women aged 15-44 years (for DLHS-2) and 15-49 years (for DLHS-3\&4 respectively). ${ }^{\star}$ Includes Rhythm/Periodic abstinence, Withdrawal and Other traditional method (for 2002-04, DLHS-2); Rhythm/Periodic and withdrawal methods (for 2007-08 and 2012-13, for DLHS-384 respectively). ${ }^{5}$ Total unmet need refers to unmet need for limiting and spacing; "Unmet need for spacing includes fecund women who are neither pregnant nor amenorrhea, who are not using any method of family planning, and say they want to wait two or more years for their next birth. It also includes fecund women who are not using any method of family planning, and say they are unsure whether they want another child or who want another child but are unsure when to have the birth. "Unmet need for limiting includes fecund women who are neither pregnant nor amenorrhea, who are not using any method of family planning, and who want no more children. 


\section{Differentials of Fertility and Contraceptive Use by Residence, Education and Economic Status}

According to the DLHS-3, the average children ever born to ever-married women aged 15-49 years was higher among illiterate women (3.2) and women from lowest wealth quintile (2.8) compared women with at least 10 years of education (1.3) and women from highest wealth index (1.7) (IIPS, 2010). The births of third and higher order also more among the ever-married women who are illiterate ( 44.3 percent) and belonging to lowest wealth index (37.1 percent) compared to ever-married women educated at least up to 10 years ( 4.9 percent), and those belonging to highest wealth quintile (8.6 percent) (IIPS, 2010). Unlike modern contraceptive use, use of traditional methods is higher in urban areas (25.7 vs. 19.6 percent in rural areas), among better-educated with ten years or more (33.4 vs. 15.8 percent among illiterates), wealthier (33.8 vs. 15.9 percent among lowest quintile) and women with one child (IIPS \& Macro, 2008). On the other hand, the preference for induced abortion also high among educated women ( 4.3 vs. 2.9 percent illiterate) and wealthier (5.0 vs. 2.2 percent among lowest quintile) women (IIPS, 2010). Lower total fertility rates also observed among urban, educated and wealthier women of West Bengal (IIPS \& Macro, 2008; IIPS \& Macro, 2001), apart from the high rates of traditional contraceptive use and induced abortions. This indicates that the fertility decline in West Bengal cannot be attributed to family planning program. The fertility preference among Bengali couples came holding hand of the elites and defused across caste and class (Basu \& Amin 2000; Chacko, 2001; Maharatna, 2007; Husain \& Dutta, 2016). Despite the greater access and knowledge to modern contraceptives, significant proportions of couples are using traditional contraceptives. Thus, it is apparent that traditional methods are playing an important role in fertility decline in West Bengal. However, the coping mechanism with contraceptive choice, method failures and abortions among urban educated traditional contraceptive users is under shadow and that still require further research.

\section{Data and Methods}

This study uses quantitative and qualitative primary data collected from Howrah Municipal Corporation area in the state of West Bengal, India. The city of Howrah or Haora (22-35'-30" north latitude and $88^{\circ}-21^{\prime}-0^{\prime \prime}$ east longtitude) is a riparian city and headquarters of the Howrah district, West Bengal. Howrah has been conceived as a twin city of Kolkata and located on the west bank of Hooghly river 
and is much older than Kolkata. Howrah Municipality was established in 1862 and became a municipal corporation in 1984 with fifty wards. As of 2011 India census, Howrah had a population of $1,072,161$ and males constitute 52.3 percent of the total population and females 47.7 percent. Howrah has an average literacy rate of 89.9 percent, higher than the national average of 74.0 percent, with male literacy of 92.4 percent and female literacy of 87.1 percent. Eight percent of the total population is under 6 years of age in Howrah (Registrar General, India, 2013).

This study conducted in ward number 26 of Howrah Municipal Corporation area of West Bengal, and the primary data collected from a total of 100 educated ever users of traditional contraceptive methods. In order to identify the eligible couples, a primary household census of 240 households conducted considering non-eligible women, refusal, non-response, and locked households. The inclusion criteria were: currently married between ages 15-49 years, the women have completed at least $10^{\text {th }}$ standard of education, and the couple ever used any traditional methods of contraceptives in their life time. From the house listing operations, a total 140 currently married women (58.3 percent of the women or couples) reported ever use of any method of traditional contraceptives and among these a total of 100 eligible women aged 18-39 years were interviewed. In this study, the term traditional methods refer to abstinence, periodic abstinence (including fertility awareness based methods), and withdrawal, while modern methods includes supply methods such as the pill, injection and intrauterine device (IUD).

Using the semi-structured interview questionnaire, information on individual and household characteristics, reproductive history, awareness, attitude, knowledge about contraceptive methods, level of satisfaction, husband-wife communication and decision making process regarding contraceptives were collected. Apart from knowledge and attitude towards contraceptives, data on patterns and histories of contraceptive behavior and consequences of the method were also collected. The study questionnaire was first prepared in English and then translated in to Bangla language and canvassed. Before conducting the main study, pre-test was carried out on $5 \%$ of the sample selected from the nearby ward, which was not included in the study. The women were interviewed at their homes for comfortable environment, privacy and confidentiality. This has also helped to achieve high response rate and only few women (two) refused to participate in the study. Apart from quantitative data from women, qualitative data collected from 10 husbands of select eligible women, to explore their experiences and perspectives on contextual issues of contraceptives with a predesigned in-depth individual interview guideline. Male members were selected on the basis of their occupation, educational level and the 
method they were using at the time of the survey. An informed verbal consent was obtained from each of the respondents before interview, with complete assurance for privacy and confidentiality. Data were entered and analyzed using SPSS for windows version 15.0 and the qualitative data from individual in-depth interviews were transcribed and translated into English and then coded and analyzed.

Descriptive statistics were used to describe the fertility and contraceptive behavior of study population. Patterns of contraceptive use, reasons for choosing the method, discontinuation of method, method failure (unintended pregnancies occurred during use of contraceptives) and outcome of pregnancy due to method failure among the study population examined according to five inter-pregnancy intervals. Figure 1 presents the definition and classification of inter-pregnancy intervals (IPI). Contraceptive use during the inter-pregnancy interval is defined as the 'use of contraceptives between the periods, marriage to first pregnancy or between the two consecutive pregnancies that is, termination of the preceding pregnancy and the conception of the next pregnancy and till date of survey. As such, the first interpregnancy interval refers to contraceptive use between marriage and first pregnancy or till the survey; Second IPI refers to contraceptive use between termination of first pregnancy and the conception of the second pregnancy or till the survey; third IPI between second and third pregnancy, the fourth IPI between third and fourth pregnancy and the fifth IPI between fourth and fifth pregnancy (last pregnancy in the study population) or till the survey date. For better understanding, the classification of the inter-pregnancy intervals explained through Figure 1. Each square on the timeline represents three months and each pregnancy has an initiation date $(\mathrm{P})$ and an outcome date $(\mathrm{O})$, at which the pregnancy ends with either a birth (O1, O3 and $\mathrm{O} 4$ in the figure) or other termination (miscarriage or induced abortion: $\mathrm{O} 2$ in the figure). The duration of time from $\mathrm{O}$ to $\mathrm{P}$ is the inter-pregnancy intervals. For the first inter-pregnancy interval, data on contraceptive behavior collected from all 100 women. Since all women did not experience all four pregnancies, the subsequent intervals, viz., second, third, fourth and fifth IPIs, the contraceptive data collected from 91,39, 9 and 4 women, respectively. 
Figure 1: Classification of inter-pregnancy intervals (WHO, 2007)

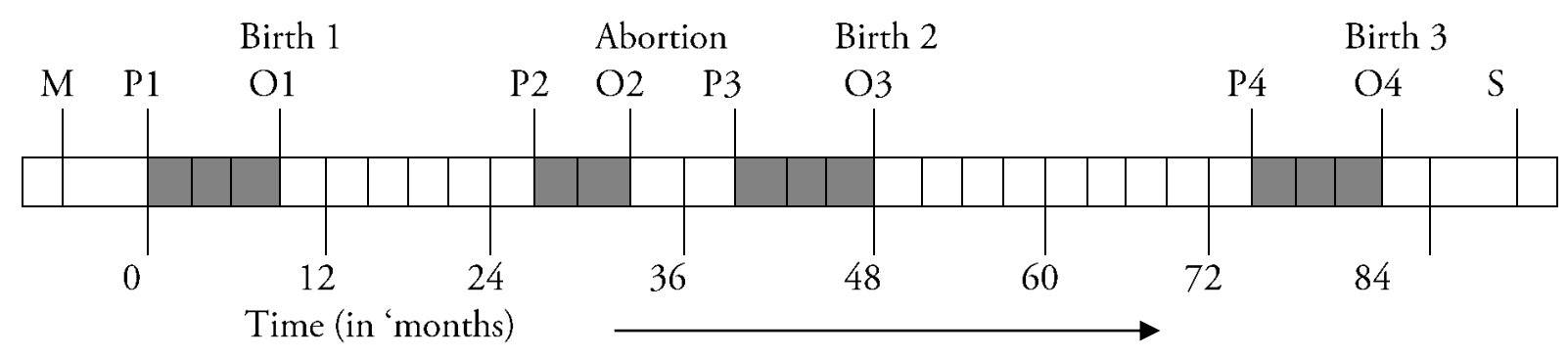

$\mathrm{M}=$ marriage; $\mathrm{P}=$ initiation date of pregnancy; $\mathrm{O}=$ outcome date of pregnancy (live birth, miscarriage or induced abortion); $\mathrm{S}=$ date of survey

Unintended pregnancy and induced abortion rates and unintended pregnancy and induced abortion ratios among the study population was also calculated. The unintended pregnancy rate and ratio were calculated per 1,000 pregnancies and women in the study population, respectively. The abortion incidence was calculated in the form of percentage of women who had a history of induced abortion. The abortion rate was computed in terms of the number of induced abortions per 1,000 pregnancies, and the abortion ratio denotes the number of induced abortions per 1,000 live births. In addition, findings from the qualitative data collected from husbands were used to supplement the quantitative results.

\section{Results}

\section{Characteristics of Study Population}

Table 3 presents the select characteristics of 100 study population interviewed i.e., eligible currently married women aged 18-39 years with 10 years of education and ever used any traditional methods of contraceptives in their life time. Majority of women (64 women) were in the age group of 30-39 and married between ages 2029 (78 women). The mean age and age at marriage of the study sample women were 31.3 and 22.2 years, respectively. More than half of the women (52 women) and two-fifths of their husbands ( $40 \mathrm{men}$ ) had class 12 education. Forty-eight women and sixty husbands had a higher level of education (38 women and 47 men were graduated; and 10 women and 13 husbands had post-graduate or professional [medicine/engineering] degree. In spite of higher education among women, only 12 women respondents reported that they worked for cash and majority ( 88 women) were housewives (Table 3). All respondents are Hindu and came under general caste 
(non-scheduled caste/tribe and backward class) category. The average household size was 4.8 and about one-fourth of the couples from joint family (Table not shown).

\section{Reproductive Behavior of Study Population}

Among the 100 women interviewed, nine women had never been pregnant, 52 women experienced one pregnancy, 30 women two pregnancies, five and four women had experienced three and four pregnancies, respectively. In all, a total of 143 pregnancy episodes was experienced of which 78.5 percent of resulted in live births, 14 percent in abortions and the remaining eight percent were miscarriages. The average number of pregnancies and children born per women was about 1.43 and 1.10 , respectively. Majority of women ( 71 women) had one child, of which 43 women had a daughter. Fifteen women had two children, of them seven had two daughters, and six had a son and a daughter. On the other hand, 11 women did not have children.

\section{Patterns of Current Contraceptive Use}

Table 3 also depicts the current use of contraceptive methods and its patterns in the study population. Of the 100 ever users of contraceptive methods interviewed, 71 women were currently using a contraceptive method. Among these, 82 percent women or their husbands were using only traditional methods (Rhythm, withdrawal or abstinence), while 10 percent of women or their husbands using only modern methods (Pill, IUD or Sterilization). Among the traditional method users, about 29 and 17 percent of women reported that they were following withdrawal and rhythm methods, respectively and about 29 percent reported a combination of both rhythm and withdrawal methods. Besides these, a smaller proportion of women reported modern methods (3-4 percent) and about nine percent of couples using both traditional and modern methods viz. combination of rhythm and condom (4.3 percent), or withdrawal and pill (1.4 percent), or rhythm, withdrawal and condom (2.9 percent). 
Table 3: Characteristics of Study Sample Population ( $N=100)$, Howrah District, West Bengal, India

\begin{tabular}{|c|c|}
\hline Characteristic & $\% \dagger$ \\
\hline \multicolumn{2}{|l|}{ Women's Age (in years) } \\
\hline $20-24$ & 9.0 \\
\hline $25-29$ & 27.0 \\
\hline $30-34$ & 30.0 \\
\hline $35-39$ & 34.0 \\
\hline Mean & 31.3 \\
\hline \multicolumn{2}{|l|}{ Age at Marriage (in years) } \\
\hline$<=19$ & 20.0 \\
\hline $20-24$ & 57.0 \\
\hline $25-29$ & 21.0 \\
\hline $30+$ & $(2.0)$ \\
\hline Mean & 22.2 \\
\hline \multicolumn{2}{|l|}{ Women's Education (in years) } \\
\hline $10-12$ & 52.0 \\
\hline $13-15$ & 38.0 \\
\hline $15+$ & 10.0 \\
\hline \multicolumn{2}{|l|}{ Husband's Education (in years) } \\
\hline $10-12$ & 40.0 \\
\hline $13-17$ & 47.0 \\
\hline Professional degree & 13.0 \\
\hline Women Working for Cash (\%) & 12.0 \\
\hline \multicolumn{2}{|l|}{ Number of Pregnancies } \\
\hline 0 & 9.0 \\
\hline 1 & 52.0 \\
\hline 2 & 30.0 \\
\hline $3+$ & 9.0 \\
\hline Mean & 1.44 \\
\hline \multicolumn{2}{|l|}{ Outcome of Pregnancies } \\
\hline Live birth & 78.5 \\
\hline Induced abortion & 13.9 \\
\hline Miscarriage & 7.6 \\
\hline \multicolumn{2}{|l|}{ Number and Sex Composition of Children } \\
\hline No child & 11.0 \\
\hline One child - No daughter & 28.0 \\
\hline One child - One daughter & 43.0 \\
\hline Two children - No daughter & 2.0 \\
\hline Two children - One daughter & 6.0 \\
\hline Two children - Two daughters & 7.0 \\
\hline Three or more children & 3.0 \\
\hline Mean & 1.10 \\
\hline Current (any method) contraceptive use $(N=100)$ & 71.0 \\
\hline \multicolumn{2}{|l|}{ Type of Contraceptive Method $(N=71)$} \\
\hline Traditional methods only & 81.7 \\
\hline Modern methods only & 9.8 \\
\hline Traditional and modern methods & 8.5 \\
\hline
\end{tabular}




\begin{tabular}{lc}
\hline Characteristic & $\% \dagger$ \\
\hline Types of Contraceptive Method $(N=71)$ & 28.6 \\
Withdrawal & 16.9 \\
Rhythm & $(2.9)$ \\
Abstinence & $(4.3)$ \\
Pill & $(2.9)$ \\
IUD & $(1.4)$ \\
Sterilization & $(4.3)$ \\
Abstinence + Withdrawal & $(4.3)$ \\
Rhythm + Condom & $(1.4)$ \\
Withdrawal + Pill & 28.6 \\
Rhythm + Withdrawal & $(2.9)$ \\
Rhythm + Withdrawal + Condom & $(1.4)$ \\
Abstinence + Rhythm + Withdrawal &
\end{tabular}

Note: †Primary data collected from currently married women aged 18-39 years (with $10+$ years of education) and reported ever use (couples) of any traditional contraceptive methods in their life time from urban areas of Howrah, Howrah district, West Bengal, India; () small number of cases; $\$$ multiple responses

\section{Contraceptive Behavior and Dynamics during the Inter-pregnancy Intervals}

\section{Patterns of Contraceptive Use and Choice of Methods}

As mentioned in the data and methods, to understand the dynamics of contraceptive behavior of the study women, data on the contraceptive behavior during each of the inter-pregnancy intervals were analyzed separately. In different inter-pregnancy intervals, couples liked to use different methods and sometimes they tried to shift from one method to the other method. Therefore, data on contraceptive behavior and history were collected from all 100 women for the first interval, i.e., from marriage to first conception. Since, all women did not experience all four pregnancies, the subsequent intervals, viz., second, third, fourth and fifth IPIs, the contraceptive data were collected from 91,39, 9 and 4 women, respectively. Table 4 presents the patterns of contraceptive use, reasons for choosing the method, consequences associated with select contraceptive methods, discontinuation, method failure and outcomes of the unwanted pregnancies among the study population during the five inter-pregnancy intervals (IPI). 
Among the 100 ever-users interviewed, 79 women each reported use of contraceptives during first and second inter-pregnancy intervals. However, from third inter-pregnancy interval onwards, all most all women (though a small number) reported use of contraceptives between the two pregnancies i.e., 38 out of 39 women and 9 out of 9 women during third and fourth inter-pregnancy intervals, respectively. By method, use of traditional methods observed to be highest in each and every interval and sometimes the couple tries to shift from one method to the other method. During the first and second inter-pregnancy intervals, about threefourth (71-72 percent, i.e., 56-57 out of 79 women) women reported use of traditional methods and considerable number of couples (17-19 percent, out of 79 women) also reported use of both traditional and modern contraceptives.

Among the traditional methods, about two-fifth (36-39 percent) of couples reported practice of withdrawal method only followed by only rhythm method (19-27 percent) during first and second IPIs. However, a large proportion of couples (37 and 30 percent during first and second IPIs, respectively) who were practicing withdrawal method were also using it with combination of rhythm method. When the women were asked about the main reasons for using the traditional methods, more than two-fifth (42-45 percent) of women during first and second IPIs stated 'no fear about side effects', followed by about one-fifth to two-fifth (20 and 42 percent during first and second IPI, respectively) of women reported 'convenient to use', and about one-fifth (19 percent) of women as 'husbands are keen to use the methods' during first and second IPIs. Apart from the above, women were also reported that 'they are advised by husbands, sisters-in-law and friends', 'women have health problem so they cannot use modern methods', and 'no risk of failure in these methods'. On the other hand, however, 13 women in all inter-pregnancy intervals and seven women particularly during first inter-pregnancy interval reported that 'doctor advised them to use traditional methods of contraceptives.

\section{Nature of Problems Faced During Contraceptive Use}

During each of the inter-pregnancy intervals, the study women were asked if they or their husbands had experienced any problems during the course of contraceptive use. Out of 79 women, a total of 35 and 25 women (44 and 32 percent, respectively) during first and second inter-pregnancy intervals reported experience of problems. When the women were asked to report the nature of problems, 66-67 percent of women (out of 35 and 25 women) during first and second inter-pregnancy intervals, reported the method failure and become pregnant. Very few respondents (8 
respondents each) in first and second inter-pregnancy intervals reported 'lack of satisfaction', 'inconvenient to use' and 'lack of privacy' as other problems.

\section{Discontinuation of Contraceptive Use and Reasons}

Respondents were also asked if they or their husband have ever stopped use of contraceptives and reasons for discontinuation. The women who reported discontinuation of contraceptives were highest in the first inter-pregnancy interval (82 percent) followed by the second inter-pregnancy interval ( 41 percent) and a small number of women during third and fourth IPIs. Out of 79 women each during first and second inter-pregnancy intervals, a total of 65 women and 32 women were reported that they or their husbands stopped using contraceptives and the main reason for discontinuation of contraceptive use was 'becoming pregnant or method failure' followed by 'wanted a child' or 'lack of satisfaction'. Out of 65 women during the first inter-pregnancy interval, 36 women $(55$ percent $)$ discontinued contraceptives as 'they desired a child, followed by 27 women (42 percent) stated 'method failurelbecome pregnant'. On the other hand, however, out of 36 women who discontinued contraceptives during the second inter-pregnancy interval, 22 women (69 percent) blamed to 'method failurelbecome pregnant' and 10 women (31 percent) reported 'wanted a child. Thus, the unintended pregnancies observed to be highest (75 percent) in third inter-pregnancy interval followed by second IPI (69 percent) and lowest (42 percent) in the first inter-pregnancy interval. Respondents were also asked about outcome of the unintended pregnancies due to contraceptive method failure. Out of 22 and 6 method failure episodes during the second and third interpregnancy intervals, 14 and 3 pregnancy episodes had undergone induced abortion compared with 2 out of 27 pregnancy episodes in the first-inter pregnancy period. 
Table 4: Patterns of Contraceptive Use, Reasons for Choosing the Method, Discontinuation of method, and Outcome of Pregnancy Due to Method Failure, According to Inter-pregnancy Intervals among the Study Population, Howrah District, West Bengal, India

\begin{tabular}{l}
\hline Contraceptive Behavior \\
Patterns/ Inter-Pregnancy \\
Intervals [IPI] \\
\hline Total number of women† \\
\hline Contraceptive Use \\
No \\
Yes \\
Type of Contraceptive Method \\
Traditional methods only \\
Modern methods only \\
Combination of methods \\
\\
Type of Traditional Method \\
Rhythm only \\
Withdrawal only \\
Rhythm \& withdrawal \\
Othersł \\
Reasons for Choice of \\
Traditional Methods \\
Convenient to use \\
No fear about side effects \\
Husband wanted \\
Did not feel to use \\
Doctor advised to use \\
Others
\end{tabular}

Problems (Women/husband)

Faced During Contraceptive Use

$$
\text { No }
$$

Yes

Types of Problem

Become pregnant/method failed

Lack of satisfaction

Inconvenient to use

etc.,)

Others (created problem

Discontinuation of

Contraceptives

$$
\text { No }
$$

Yes

Reasons for Discontinuation

Become pregnant/method failed

Wanted child

Lack of satisfaction/don't

like

$\begin{array}{rrrrrr}15(26.8) & 11(19.3) & 6(19.4) & (-) & (-) & 32(21.1) \\ 20(35.7) & 22(38.6) & 12(38.7) & 1(20.0) & (-) & 55(36.2) \\ 21(37.5) & 17(29.8) & 11(35.5) & 2(40.0) & (-) & 51(33.6) \\ (-) & 7(12.3) & 2(6.5) & 2(40.0) & 3(100.0) & 14(9.2) \\ & & & & & \\ 14(19.7) & 22(31.0) & 10(29.4) & 1(20.0) & 2(66.7) & 49(26.6) \\ 32(45.1) & 30(42.3) & 15(44.1) & 3(60.0) & 1(33.3) & 81(44.0) \\ 14(19.7) & 15(21.1) & 4(11.8) & 1(20.0) & (-) & 34(18.5) \\ 9(12.7) & 4(5.6) & 2(5.9) & 1(20.0) & (-) & 16(8.7) \\ 7(9.9) & 3(4.2) & 2(5.9) & 1(20.0) & (-) & 13(7.1) \\ 3(4.2) & 7(9.9) & 6(17.6) & 1(20.0) & (-) & 17(9.2)\end{array}$

$\begin{array}{rrrrrr}56(70.9) & 57(72.2) & 31(79.5) & 5(55.6) & 3(100) & 152(72.7) \\ 8(10.1) & 8(10.1) & 5(12.8) & 2(22.2) & (-) & 23(11.0)\end{array}$

$15(19.0) \quad 14(17.7) \quad 3(7.7) \quad 2(22.2) \quad(-) \quad 34(16.3)$

$\begin{array}{rrrrrr}21(21.0) & 12(13.2) & 1(2.6) & (-) & 1(25.0) & 35(14.4) \\ 79(79.0) & 79(86.8) & 38(97.4) & (100.0) & 3(75.0) & 208(85.6) \\ & & & & & \\ 56(70.9) & 57(72.2) & 31(79.5) & 5(55.6) & 3(100) & 152(72.7) \\ 8(10.1) & 8(10.1) & 5(12.8) & 2(22.2) & (-) & 23(11.0) \\ 15(19.0) & 14(17.7) & 3(7.7) & 2(22.2) & (-) & 34(16.3)\end{array}$

$\begin{array}{llllll}44(55.7) & 54(68.4) & 29(76.3) & 7(75.0) & 2(75.0) & 136(65.4)\end{array}$

$35(44.3) \quad 25(31.6) \quad 9(23.7) \quad 2(25.0) \quad 1(25.0) \quad 72(34.6)$

$24(67.7) \quad 17(66.7) \quad 8(87.5) \quad 2(100) \quad 1(100) \quad 52(71.5)$

$3(9.7) \quad 1(4.2) \quad 1(12.5) \quad(-) \quad(-) \quad 5(7.7)$

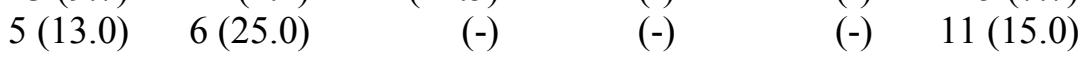

$3(9.7) \quad 1(4.2) \quad(-) \quad(-) \quad(-) \quad 4(5.7)$

$\begin{array}{llllll}14(17.7) & 47(59.5) & 30(78.9) & 6(66.7) & 3(100.0) & 100(48.1)\end{array}$

$\begin{array}{llllll}65(82.3) & 32(40.5) & 8(21.1) & 3(33.3) & (-) & 108(51.9)\end{array}$

$27(41.5) \quad 22(68.8) \quad 6(75.0) \quad 2(66.7) \quad(-) \quad 57(52.8)$

$36(55.4) \quad 10(31.3) \quad 2(25.0) \quad 1(33.3) \quad(-) \quad 49(45.4)$

$\begin{array}{llllll}2(3.1) & (-) & (-) & (-) & (-) & 2(1.9)\end{array}$ 


\begin{tabular}{lrrrrrr}
\hline $\begin{array}{l}\text { Contraceptive Behavior } \\
\text { Patterns/ Inter-Pregnancy } \\
\text { Intervals [IPI] }\end{array}$ & First IPI & $\begin{array}{c}\text { Second } \\
\text { IPI }\end{array}$ & Third IPI & $\begin{array}{c}\text { Fourth } \\
\text { IPI }\end{array}$ & Fifth IPI & \multirow{2}{*}{$\begin{array}{c}\text { Total No. } \\
\text { of } \\
\text { intervals } \dagger \dagger\end{array}$} \\
\cline { 2 - 6 } $\begin{array}{l}\text { Pregnancy Ends with Induced } \\
\text { Abortion }^{* *}\end{array}$ & & & & & & \\
$\quad$ No & $25(92.6)$ & $8(36.4)$ & $3(50.0)$ & $(100.0)$ & $(-)$ & $38(66.7)$ \\
$\quad$ Yes & $2(7.4)$ & $14(63.6)$ & $3(50.0)$ & $(-)$ & $(-)$ & $19(33.3)$ \\
\hline
\end{tabular}

Notes: See Table 3; ${ }^{*}$ Contraceptive use between IPIs i.e., duration from marriage/last birth/last pregnancy outcome to conception/till survey see data and methods for details; (-) No cases; $\uparrow$ total number of women during IPIs ( $\dagger$ specific or $\uparrow \nmid a l l) ; ~ ¥$ Others' include 'periodic abstinence' and 'combination of periodic abstinence and withdrawal method methods; $\$$ reported multiple responses; 9 'Others' include 'no failure risk', 'cannot use other methods due to health problems', 'habituated and lactational amenorrhea'; ' among the unintended pregnancy episodes due to method failure

\section{Couples Perspectives on Choice and Decision about Contraceptive Methods}

From the above quantitative analyses, it was observed that a considerable number of couples in the study area used traditional contraceptives, raising the question why educated urban couples do not use the most effective modern contraceptive methods? The reasons were assessed and illustrated for their decisions from the responses captured in open-ended questions from women and in-depth interviews from husbands, with appropriate transcribed verbatim quotations. The most common reason for preferring traditional methods as reported were 'fear of side effects', followed by 'knowledge about the method', 'negative experiences and myths', and 'perceived problems associated with modern contraceptive methods'. The women also mentioned that they completely depended on the husband to decide on contraceptive use. When the questions were raised on reasons for this, the women replied that husbands are more knowledgeable than them. It was also observed that sometimes the couple tries to shift from one method to the other method and considerable number of couples also reported using both traditional and modern contraceptives. When the women were asked why they use the method in combination they answered that it was due to 'husband's dislikelopposition about the methods and husband's decision' followed by 'to obey husband's words' and 'health concerns'. On the other hand, however, one woman reported that without her husband's knowledge she was consuming oral contraceptive pills (OCP). Few indicated that because they did not have regular sexual activity and hence had no use for contraception. However, the opinion of men differed and they reported that they discussed with their wives about the methods, negative experiences and incidences among relatives and neighbors before deciding on the chosen method. Following are 
some of the excerpts to illustrate different perceptions about contraceptive use by respondents:

"...our husband decides which contraceptive method we will use, and we don't have say in this. Our husbands only inform us..." "... I had not used any method or thing. My husband is a doctor, he knows everything about this matter and he takes all the decisions..."

"... usually couple use rhythm method, and during unsafe days practice either withdrawal or condom ..."

"... sometime we scare about the method. But we cannot say to our husbands about these. So, we are using the method according to our husband's desire as well as using the method we feel more reliable without taking consent of our husbands..."

"... intimacy between us is very rare. My child is very young and very naughty, so I am really busy with my child since 5 O'clock of morning. After office, my husband also goes to play card with his friends. He comes back around $11.00 \mathrm{pm}$ and by that time I am too tired to think for any sexual intimacy..."

"... before using the method, I had discussed with my wife but the decision was taken by me only. She also heard about the side effects of modern methods and I think because of that she also agreed with me..."

"... I was confident that I could withdraw properly. So, I had used the method. Later I had talked with my wife and she had answered if I think this is good then she has no problem..."

It has also been observed that social net-working among women and men was high in the community and men used to talk about contraceptives with their friends and women also talk with their sisters-in-law, friends and neighbors. However, the individual in-depth interviews also highlighted lack of knowledge and misconception about modern methods was prevalent in the community. Even men reported that modern methods (OCP, injectable and IUD) had side effects and they did not want their wife to suffer. They heard unfounded or exaggerated rumors about such side effects and deterred from even trying these methods. Some of them indicated prior to use traditional methods they had consulted with physicians on 
available options. The following interview excerpts illustrate the concerns and perceptions on contraceptive use and methods:

"... I came to know about the method from doctor and obviously from some friends..."

"... I have lot of friends, who are doctors. Before my marriage, I had discussed with them about these contraceptives. They told me about some people who faced problems because of modern methods of contraceptives. After hearing all these I had decided to use rhythm or safe period method. Since, I could not tolerate the side effects when using the modern methods..."

"... we used this method because we felt this is the easiest method. After marriage, I used condom, but there are several problems viz. buying, disposing; and we had started using this withdrawal method..."

\section{Prevalence of Unplanned Pregnancy and Induced Abortion}

It is well known the chance of an unexpected pregnancy is almost non-existent for couples who rely on sterilization, very low for 'users of the IUD, injectable or implant', moderate for 'pill and condom users', and very high 'if the couples rely upon periodic abstinence, withdrawal or spermicidal' (Sabatello, 1992). Table 5 presents the summary on contraceptive method failure/unintended pregnancies, induced abortion by type of contraceptive methods among study women during their reproductive periods. It can be observed from the Table 4 that the prevalence of unintended pregnancies and induced abortions were very high during different inter-pregnancy intervals. Among the 100 study women interviewed, a total of 243 pregnancies episodes were observed during the five inter-pregnancy intervals and women reported use of contraceptives during 208 episodes. Of these 208 pregnancy episodes, women discontinued contraceptives in 108 pregnancy episodes and a total of 57 unintended pregnancy episodes were observed due to 'method failure'. These 57 episodes of method failure were from 42 women, since few women had multiple unintended pregnancy episodes. In the study population, 15 women (26 percent) faced more than one method failure (multiple) in their lifetime. Out of 57 method failures, 37 pregnancy episodes (65 percent) were with traditional methods of contraceptives, compared with 16 episodes (28 percent) among modern method users. Out of the total 57 unintended pregnancy episodes, women had undergone induced abortion in 19 episodes ( 33 percent) and 13 episodes ( 68 percent) of which 
were due to traditional methods. During in-depth individual interviews, women who have at least one child reported, "...become pregnant after a very short period..., which compelled to undergo abortion...", "...what to do, we went to clinic for abortion". Contrary, women who become pregnant for the first time due to method failure were more likely to deliver the baby. Since, there was a norm in this community that the first pregnancy should not be aborted. If anyone aborted it then she would not be able to become mother in future. Helplessly, respondents from first inter-pregnancy interval stated "... what to do. It was my first pregnancy. So, I was not allowed to abort! I delivered the child...".

The calculated unintended pregnancy rate and ratio for the study population were 235 per 1,000 pregnancies and 570 per 1,000 women, respectively. Similarly, the calculated rate of induced abortion was 78 per 1,000 pregnancies with an abortion ratio of 99 per 1,000 live births (Table 5). The West Bengal abortion statistics for the period 2009-10 show an induced abortion ratio of 125 and 35 abortions per 1,000 live births for Haora district and West Bengal State, respectively (Johnson, 2014). Tragler (2011) in a sub-urban slum community in Mumbai city of India showed an induced abortion ratio of 85.9 per 1000 live births (i.e., 60 induced abortions among 698 live births). Similarly, Behera, Bharat \& Gawde (2015) in a minority dominated urban slum community in Mumbai showed an induced abortion ratio of 162.8 per 1,000 live births in the past five years. It has to be noted here that the incidence rates of unintended pregnancies and induced abortions might be higher in the study area, since the study population comprises urban educated and currently married women aged $18-39$ years. 
Table 5. Summary Distribution on Method Failure, Induced Abortion and Type of Contraceptive Method among the Study Population, Howrah District, West Bengal, India

\begin{tabular}{|c|c|}
\hline Characteristic & Total \% $(\mathrm{N})$ \\
\hline Total number of women interviewed* $(\%)$ & $100(100.0)$ \\
\hline Total number of pregnancy episodes $\dagger(\%)$ & $243(100.0)$ \\
\hline Total number of live births $\dagger$ & $191(78.5)$ \\
\hline$\%$ of contraceptives use $(\mathrm{N})$ & $85.6(208)$ \\
\hline$\%$ of contraceptives discontinuation $¥(\mathrm{~N})$ & $51.9(108)$ \\
\hline$\%$ unintended pregnancy episodes experience $\$(\mathrm{~N})$ & $52.8(57)$ \\
\hline \multicolumn{2}{|l|}{$\%$ frequency of unintended pregnancy episodes $\$(\mathrm{~N}=57)$} \\
\hline At least once & $73.7(42)$ \\
\hline More than once & $26.3(15)$ \\
\hline \multicolumn{2}{|l|}{$\%$ type of contraceptive method used $(\mathrm{N}=57)$} \\
\hline Traditional methods only & $64.9(37)$ \\
\hline Modern methods only & $28.1(16)$ \\
\hline Traditional and modern methods & $7.0(4)$ \\
\hline Unintended pregnancy rate (per 1,000 pregnancies) & 235 \\
\hline Unintended pregnancy ratio (per 1,000 women) & 570 \\
\hline Unintended pregnancy ratio (per 1,000 ever pregnant women) & 626 \\
\hline \multicolumn{2}{|l|}{$\%$ Termination (induced abortion) of unintended pregnancy episodes $(N=57)$} \\
\hline No & $66.7(38)$ \\
\hline Yes & $33.3(19)$ \\
\hline \multicolumn{2}{|l|}{$\%$ Type of contraceptive method used $(N=19)$} \\
\hline Traditional methods only & $68.4(13)$ \\
\hline Modern methods only & $10.5(4)$ \\
\hline Traditional and modern methods & $21.1(2)$ \\
\hline Percentage of abortions (per 100 pregnancies, excluding miscarriages) & 8.4 \\
\hline Induced abortion ratio (per 1,000 live births) & 99 \\
\hline Induced abortion rate (per 1,000 pregnancies) & 78 \\
\hline Induced abortion rate (per 1,000 women) & 190 \\
\hline Induced abortion rate (per 1,000 ever pregnant women) & 209 \\
\hline
\end{tabular}

Notes: *Primary data collected from currently married women aged 18-39 years (educated with $10+$ years of education) and couples ever used any traditional contraceptive methods in their life time in urban areas of Howrah district, West Bengal, India; †during 1-5 inter-pregnancy intervals by the study women ( $N=100)$; due to contraceptive method failure and other reasons; $\$$ Unintended pregnancy due to contraceptive method failure; Sregnancy episodes ends with induced abortion; Unintended pregnancy rate/ratios and induced abortions rate/ratios calculated using Table $3 \& 4$ and the rates/ratios refers to among the study women (urban and educated currently married women age 18-39 years) only 


\section{Discussion}

Contraceptive use in the East Indian state of West Bengal is higher than the national average and the patterns of contraceptive dynamics is also distinct from other states in India (Ram, Shekhar \& Chowdhury 2014). While the Government of India is focusing on expanding the basket of modern contraceptives, considerable number of couples continue to use traditional methods and prevalent since for a long time due to perceived 'body conscious' and concerned about 'side effects' of modern methods (Basu, 2005; Maharatna, 2007; Basu, 2011) and cannot be equated with insufficient motivation to limit family size (Basu, 2011). This study focused to explore patterns of contraceptive use and associated outcomes during the inter-pregnancy intervals among urban educated couples of Howrah, West Bengal, India, which is a little researched area globally and including India.

Despite the higher accessibility, availability and affordability of modern contraceptive methods and levels of literacy in the study population, a considerable number of elite couples reported using traditional methods of contraception, such as withdrawal or rhythm methods. The positive association between educational attainment and use of traditional methods of contraceptives is consistent with studies conducted in other parts of the country (Bongaart and Bruce, 1995; Chacko, 2001; Basu, 2005; Pallikadavath \& Stones, 2006). There has a number of reasons like 'fear of side effects', 'knowledge about the method', lack of other method choices and availability of choices', for the preference of traditional methods, and 'perceived problems associated with modern contraceptive method', 'negative experiences and myths', 'infrequent sex' and 'opposition from husband' as well as 'safety concerns' as the reasons for non-use of modern methods. Similar reasons have been observed in other national and state level studies (Chacko, 2001; Basu, 2011; Rai \& Unisa, 2013).

This study also indicates that the husband's opinion was the dominant factor in the choice of contraception methods and highly dependent on diffusion of knowledge through neighborhood network of couples (i.e., men discuss with friends and women with immediate neighbors and sisters-in-law). Moreover, misperception about the methods spread within the community by diffusion (Maharatna, 2007). Entwisle, Rindfuss, Guilkey et al., (1996) has shown how a particular type of social network affects a particular method in a village in Thailand. Thus, diffusion of knowledge though social network had enormous influence on contraceptive choice decision in the study area. These results demonstrate the lower levels of comprehensive knowledge and misconceptions about modern contraceptives, especially among men. Moreover, motivation and participation of men in women's reproductive 
health issue is very high and in most of the cases men take decision about reproductive wellbeing of women. Therefore, the choice of contraceptive is fully in the hand of men, women are only informed about selected contraceptive method.

The traditional contraceptives cost nothing and are easy to understand, but their failure rate are extremely high and cannot be totally relied for successful family planning. Findings of this study also reveal that the incidence of unintended pregnancy was the main reason for stopping or switching contraceptive methods, especially among women who used only traditional methods. Previous research also indicates that unintended pregnancies are largely because of the choice of contraceptive methods (Ranjit, Bankole, Darroch \& Singh, 2001); contraceptive nonuse, inconsistent use, and reliance on ineffective contraceptive methods (Trussel \& Vaughan 1999). This study also shows a high prevalence of method failure and induced abortions, particularly among traditional contraceptive users and similar findings observed in several studies (Fu, Darroch, Haas, \& Ranjit, 1999; Chacko, 2001; Duggal \& Ramachandran, 2004; Creanga, Acharya, Ahmed \& Tsui, 2007; Sedgh, Henshaw, Singh, Åhman \& Shah, 2007).

The decision to use permanent contraception requires couples to be absolutely certain that they do not want any more children. In the Indian context, many studies have shown that gender preference is the main reason for not accepting a permanent method (Clark, 2000; Chacko, 2001; Bhat \& Zavier 2003; Jayaraman, Mishra \& Arnold 2009 among others) and opt induced abortion until they have sufficient boys (Das Gupta, 1987; Arnold, Kishor \& Roy, 2002; Chacko, 2001; Oomman \& Ganatra, 2002 among others) or to space between children (Arnold, Kishor \& Roy, 2002; Ganatra \& Hirve, 2002; Ravindran \& Balasubramanian, 2004). According to the NFHS-3, the state has recorded total fertility rates was below replacement level of fertility ( 1.6 children per woman) in urban areas, while rural areas were still struggling to limit fertility ( 2.5 children per woman). Majority of couples ( 82 percent) want fewer children (ideal family size of two children or less) and about three-fourths (72-73 percent) of currently married women and men do not want no more children. However, there is a fairly strong preference for sons in the state, 76 percent of women and 70 percent of men would like to have at least one son and seventeen percent of women and men want more sons than daughters (IIPS \& Macro, 2008). However, there is a different scenario in the study population. It had been observed that 81 percent of women expressed that they do not want more children and only 17 percent had desire for more children, among them 11 percent do not have children. The prevalence of the small family norm is also very high with couples reporting they do not want another child, when they have at least one 
surviving child. Gender preferences is low in the study population and more than half (51 percent) do not have a son and 36 percent of women had at least one son.

This indicates that the absence of gender preferences enabling the couple's motivation towards small family norm and due to the higher motivation and societal pressures, couples intends to regulate their unintended pregnancies with only ramification, i.e., induced abortion, as a possible way to limit family size, rather than using effective modern contraceptives including sterilization. However, if the women first time-pregnant or do not have any living child, women continue their pregnancy. Since, there has a norm in the community that if the first pregnancy aborted, women may fail to conceive in future. On the other hand, women who has at least a living child opted for abortion to limit their size of family, few of them opted for multiple induced abortion and most of these women used traditional methods of contraceptives only. Therefore, the choice of contraceptives is determining number of pregnancies to maintain the desired family size in the study population hence, the prevalence of unintended pregnancies and abortions were higher and the study women considered abortion as process of birth limiting rather than spacing. This confirms findings on the relationship between contraceptive use and induced abortion such that a rise in contraceptive use and/or effectiveness leads to a decline in induced abortion and vice versa. When fertility levels in the population is changing, the relationship between contraceptive use and abortion may take a variety of forms, frequently involving a simultaneous increase/decrease in both (Marston \& Cleland, 2003).

This study has the following limitations. First, the findings of the study cannot be generalized due to its small sample size, the study population being too homogenous, and drawn from urban educated currently married women aged 18-35. Besides, results may not be comparable with other states of India, where the use of traditional method of contraception is high (viz., Goa, Assam, Himachal Pradesh, Kerala and Tripura). Secondly, the findings of the study were based on retrospective selfreported data on contraceptive use, choices and outcomes during inter-pregnancy intervals and therefore may be subject to recall bias. Finally, the researcher had collected data from respondents suggesting possible interviewer bias. However, the researcher was trained and followed a strict protocol to reduce the likelihood of such bias.

Despite these limitations, this study indicates that a sizeable proportion of Bengali couples rely on less-effective/traditional contraceptive methods, resulting in high prevalence of unintended pregnancies and some couples considered abortion to limit 
their family size. At the global level, Bongaarts and Johansson (2000) estimated the use of traditional methods may reach to 14 per cent in 2015 from 9 percent in 2000. In India also Ram, Shekhar and Chowdhury (2014) estimated about 13.0 and 2.6 million couples (out of total 196 and 15 million eligible couples) were using traditional methods and about 29 and 3.2 million couples were having unmet need for spacing methods of family planning, at the all-India and West Bengal state levels, respectively. In all, about 53 and 5.7 million couples required to use modern spacing methods of family planning in achieving the reproductive goals at the national and West Bengal state levels, respectively. Therefore, to meet growing contraceptive needs, policy makers and programmers should concentrate on providing services and education to support both traditional and modern methods in order women may have a choice on contraceptive methods.

The state of West Bengal has achieved its replacement level of fertility, without overt coercion on sterilization. In the study area also some couples reported practice of rhythm method for longer durations, even more than six years uninterruptedly after discussing with doctors/physicians. This finding is quite similar to the argument that traditional methods can be effective if used with dedication and comprehensive knowledge (Johnson-Hanks, 2002), with couples higher involvement and motivation, and knowledge about ovulation cycle (WHO \& RH, 2011; JohnsonHanks, 2002). Traditional methods are much more effective than using no method at all, and the WHO's family planning handbook (WHO \& RH, 2011) places the fertility awareness methods above some modern methods such as female condoms and diaphragms. On the other hand, female sterilization is the dominant method in most Indian states (Ram, Shekhar \& Chowdhury 2014). However, the problem with an early sterilization viz., familial concerns of early fertility decisions, the possible age-structural impact on dependent populations and the economic burden, the possible rise in divorce and the increased number of cases of regret after sterilization (Matthews, Padmadas, Hutter, et al., 2009) has to be considered. Programs and policies that remove barriers to initiating effective contraceptive use are needed for women to realize their reproductive goals and India to achieve Millennium Development Goal 5, which calls for universal access to contraceptive services. 


\section{Acknowledgement}

The author would like to thank to Ministry of Health and Family Welfare, Government of India and International Institute for Population Sciences (IIPS), Mumbai, India for providing contingency grant to undertake this study, I am also thankful to Prof. Sulabha Parasuraman and Prof. Sayeed Unisa for providing guidance and critical inputs; Smt. Jayanthi Mukherjee, for constant support and encouragement and anonymous reviewers for their critical comments and suggestions.

\section{References}

Arnold, F. Kishor, S. \& Roy, TK. (2002). Sex-selective abortions in India, Population and Development Review, 28(4), 759-785.

Basu, A. M. (2005). Ultramodern contraception: Social class and family planning in India. Asian Population Studies, 1(3), 303-323.

Basu, A. M., \& Amin, S. (2000). Conditioning factors for fertility decline in Bengal: History, language identity, and openness to innovations. Population and Development Review, 26(4), 761-794.

Basu, S. (2011). High prevalence of traditional contraceptive methods and low fertility: factors affecting choice of traditional methods in Urban West Bengal, India. In Annual Meeting of Population Association of America (March 31 April 2, 2011), Washington, DC. APHA. Retrieved from http://paa2011.princeton.edu/papers/112588

Behera, D., Bharat, S., \& Gawde, N. C. (2015). Induced abortion practices in an urban Indian slum: Exploring reasons, pathways and experiences. Journal of family \& reproductive health, 9(3), 129.

Bhat, P. N. M. and Zavier, A. J. F. (2003). Fertility decline and gender bias in Northern India. Demography, 40(4): 637-657.

Biswas, D. K., Bhunia, R., \& Mukherjee, A. (2016). High prevalence of abortion among primigravida and teen aged girls in the district of Purba Medinipur, West Bengal; India. Indian Journal of Public Health Research \& Development, 7(1), 74-79.

Bongaarts, J., \& Bruce, J. (1995). The causes of unmet need for contraception and the social content of services. Studies in family planning, 57-75. 
Bongaarts, J. \& Johannson, E. (2000) Future trends in contraception in the developing world: prevalence and method mix, working Paper No. 141, The Population Council, New York.

Chacko, E. (2001). Women's use of contraception in rural India: a village-level study. Health \& place, 7(3), 197-208.

Clark, S. (2000). Son preference and sex composition of children: Evidence from India. Demography, 37(1), 95-108.

Conde-Agudelo, A., Rosas-Bermúdez, A., \& Kafury-Goeta, A. C. (2006). Birth spacing and risk of adverse perinatal outcomes: a meta-analysis. Jama, 295(15), 1809-1823.

Creanga, A. A., Acharya, R., Ahmed, S., \& Tsui, A. O. (2007). Contraceptive discontinuation and failure and subsequent abortion in Romania: 1994-99. Studies in family planning, 38(1), 23-34.

Das Gupta, M. (1987). Selective discrimination against female children in rural Punjab, India. Population and Development Review, 13(1), 77-100. Explaining son preference in rural India.

Duggal, R., \& Ramachandran, V. (2004). The abortion assessment project-India: key findings and recommendations. Reproductive Health Matters, 12(24), 122129.

Entwisle, B., Rindfuss, R. R., Guilkey, D. K., Chamratrithirong, A., Curran, S. R., \& Sawangdee, Y. (1996). Community and contraceptive choice in rural Thailand: a case study of Nang Rong. Demography, 33(1), 1-11.

Fu, H., Darroch, J. E., Haas, T., \& Ranjit, N. (1999). Contraceptive failure rates: new estimates from the 1995 National Survey of Family Growth. Family Planning Perspectives, 56-63.

Ganatra, B., \& Hirve, S. (2002). Induced abortions among adolescent women in rural Maharashtra, India. Reproductive health matters, 10 (19), 76-85.

Hogue, C. J., Schoenfelder, J. R., Gesler, W. M., \& Shachtman, R. H. (1978). The interactive effects of induced abortion, inter-pregnancy interval and contraceptive use on subsequent pregnancy outcome. American journal of epidemiology, 107(1), 15-26.

Huber, L. R. B., Hogue, C. J., Stein, A. D., Drews, C., Zieman, M., King, J., \& Schayes, S. (2006). Contraceptive use and discontinuation: findings from the contraceptive history, initiation, and choice study. American journal of obstetrics and gynecology, 194(5), 1290-1295.

Husain, Z., \& Dutta, M. (2016). Fertility control in a risk society: analysing contraception choice of urban elites in India. Springer. 
India, Registrar General. (2013). Census of India 2011: Final population totalsIndia data sheet. Office of the Registrar General Census Commissioner, India. Indian Census Bureau.

International Institute for Population Sciences (IIPS) (1995). National Family Health Survey MCH \& Family Planning (NFHS-1), 1992-1993: India. Mumbai: International Institute for Population Sciences.

International Institute for Population Sciences (IIPS), (2000). National Family Health Survey (NFHS-2), 1998-1999: India. Mumbai: International Institute for Population Sciences.

International Institute for Population Sciences (IIPS), (2007). National Family Health Survey (NFHS-3), 2005-2006: India. Mumbai: International Institute for Population Sciences.

International Institute for Population Sciences (IIPS), (2016a). National Family Health Survey (NFHS-4), 2015-2016: India (Fact sheet). Mumbai: International Institute for Population Sciences.

International Institute for Population Sciences (IIPS) and Macro International. 2001. National Family Health Survey (NFHS-2), India, 1998-1999: West Bengal. Mumbai: IIPS.

International Institute for Population Sciences (IIPS) and Macro International. 2008. National Family Health Survey (NFHS-3), India, 2005-2006: West Bengal. Mumbai: IIPS.

International Institute for Population Sciences (IIPS), (2016b). National Family Health Survey, 2015-2016: West Bengal (Fact sheet). Mumbai: International Institute for Population Sciences.

International Institute for Population Sciences (IIPS). (2000). DLHS-RCH Phase1 Round-2, 2004-05: West Bengal. Mumbai: International Institute for Population Sciences, Mumbai, India.

International Institute for Population Sciences (IIPS), (2010). District Level Household and Facility Survey 2007-2008 (DLHS-3): West Bengal. Mumbai, India: IIPS.

International Institute for Population Sciences (IIPS), (2014). District Level Household and Facility Survey 2012-2013 (DLHS-4, Fact sheet): West Bengal. Mumbai, India: IIPS.

Jayaraman, A., Mishra, V., \& Arnold, F. (2009). The relationship of family size and composition to fertility desires, contraceptive adoption and method choice in South Asia. International perspectives on sexual and reproductive health, 35(1), 29-38. 
Johnson-Hanks, J. (2002). On the modernity of traditional contraception: Time and the social context of fertility. Population and Development Review, 28(2), 229249.

Johnston, W. R., 2014, West Bengal abortion percentages by district, 2009-2011. In: India abortions and live births by district, 1991-2014. Retrieved from http://www.johnstonsarchive.net/policy/abortion/india/ab-indiad2westbengal.html

Marston, C. (2007). Report of a WHO Technical Consultation on Birth Spacing Geneva Switzerland 13-15 June 2005.

Marston, C., \& Cleland, J. (2003). Relationships between contraception and abortion: a review of the evidence. International family planning perspectives, 613.

Matthews, Z., S Padmadas, S., Hutter, I., McEachran, J., \& J Brown, J. (2009). Does early childbearing and a sterilization-focused family planning programme in India fuel population growth? Demographic Research: 20(28)

Maharatna, A. (2007). Population, economy and society in West Bengal since the 1970s. The Journal of Development Studies, 43(8), 1381-1422.

Mishra, V. K., Retherford, R. D., Nair, P. S., \& Feeney, G. (1999). Reasons for discontinuing and not intending to use contraception in India. National Family Health Survey Subject Reports Number 13, International Institute for Population Sciences Mumbai, India \& East-West Center Program on Population Honolulu, Hawaii, U.S.A

Oomman, N., \& Ganatra, B. R. (2002). Sex selection: The systematic elimination of girls. Reproductive Health Matters, 10(19), 184-197.

Pallikadavath, S., \& Stones, R. W. (2006). Maternal and social factors associated with abortion in India: a population-based study. International Family Planning Perspectives, 120-125.

Peterson, H. B., Darmstadt, G. L., \& Bongaarts, J. (2013). Meeting the unmet need for family planning: now is the time. The Lancet, 381(9879), 1696-1699.

Population Research Centre \& IIPS. (1994). National Family Health Survey (NFHS-1), 1992-1993: West Bengal. Mumbai: International Institute for Population Sciences.

Rai, R. K., \& Unisa, S. (2013). Dynamics of contraceptive use in India: apprehension versus future intention among non-users and traditional method users. Sexual \& Reproductive Healthcare, 4(2), 65-72.

Ram, F., Shekhar, C., \& Chowdhury, B. (2014). Use of traditional contraceptive methods in India \& its socio-demographic determinants. The Indian Journal of Medical Research, 140(Suppl 1), S17-S28. 
Ranjit, N., Bankole, A., Darroch, J. E., \& Singh, S. (2001). Contraceptive failure in the first two years of use: differences across socioeconomic subgroups. Family planning perspectives, 19-27.

Ravindran, T. S., \& Balasubramanian, P. (2004). "Yes" to abortion but "no" to sexual rights: the paradoxical reality of married women in rural Tamil Nadu, India. Reproductive Health Matters, 12(23), 88-99.

Rutstein S. (2005). Effects of preceding birth intervals on neonatal, infant and under-five mortality and nutritional status in developing countries: evidence from the demographic and health surveys. International Journal of Gynecology and Obstetrics, 89, S7-S24.

Registrar General of India (various years). Sample register and system. New Delhi: Government of India.

Sedgh, G., Henshaw, S., Singh, S., Åhman, E., \& Shah, I. H. (2007). Induced abortion: estimated rates and trends worldwide. The Lancet, 370(9595), 13381345.

Tragler, A. (2011). A study on Sex Ratio at Birth in Suburban Slums of Mumbai. Indian Journal of Public Health, 55, 128-31.

Trussel, J. \& Vaugh, B. (1999). Contraceptive failure, method-related discontinuation and resumption of use: Results from the 1995 National Survey of Family Growth. Family Planning Perspectives, 31, 64 - 72, 93.

Visaria, L., Ramachandran, V., Ganatra, B., \& Kalyanwala, S. (2004). Abortion in India: emerging issues from qualitative studies. Economic and Political Weekly, 5044-5052.

Weisband, Y. L., Keder, L. M., Keim, S. A., \& Gallo, M. F. (2017). Postpartum intentions on contraception use and method choice among breastfeeding women attending a university hospital in Ohio: a cross-sectional study. Reproductive health, 14(1), 45.

Wendt, A., Gibbs, C. M., Peters, S., \& Hogue, C. J. (2012). Impact of Increasing Inter-pregnancy Interval on Maternal and Infant Health. Paediatric and perinatal epidemiology, 26(s1), 239-258.

White, K., Teal, S. B., \& Potter, J. E. (2015). Contraception after delivery and short interpregnancy intervals among women in the United States. Obstetrics and gynecology, 125(6), 1471.

Whitworth, A., \& Stephenson, R. (2002). Birth spacing, sibling rivalry and child mortality in India. Social Science \& Medicine, 55(12), 2107-2119.

World Health Organization \& Reproductive Health (WHO \& RH). (2011). Family planning: A global handbook for providers: Evidence-based guidance developed through worldwide collaboration. Baltimore and Geneva: Johns Hopkins Bloomberg School of Public Health/Center for Communication Programs. 
World Health Organization. (2012). Safe abortion: technical and policy guidance for health systems. 2nd edition, Geneva: WHO. Retrieved from http://apps.who.int/iris/bitstream/10665/70914/1/9789241548434_eng.pdf. 